\title{
Diagnóstico y terapia del virus papiloma humano
}

\author{
Marcela Concha $R$.
}

\section{Diagnosis and treatment of human papilloma virus}

The identification and treatment of human papillomavirus (HPV) infections and HPV-associated neoplasm are complex. Difficulties in diagnosis and treatment of HPV-associated diseases arise from inabilities to detect HPV efficiently, the lack of specific antiviral drugs active against HPV and the high rates of recurrence and persistence of HPV infections after treatment. We present a review of therapies for HPV infections.

Key words: Papillomavirus, cutaneous warts, genital warts, treatment of common and anogenital warts.

Palabras claves: Virus papiloma, verrugas cutáneas, verrugas genitales, tratamiento de verrugas cutáneas y genitales.

\section{Estructura y clasificación del virus papiloma humano}

$\mathbf{E}$ 1 virus papiloma humano (VPH) es un virus de tamaño pequeño, no encapsulado, con una estructura icosaédrica y una doble cadena de ADN circular de 7.500 a 8.000 pb. Este virus pertenece a la familia de los Papovaviridae, incluida en el género Papilomavirus. Son parásitos especie-específicos, ampliamente distribuidos en la naturaleza e infectan tanto a aves como mamíferos. Usualmente, el resultado de la infección es la formación de un crecimiento benigno, verruga, o papiloma, ubicado en cualquier lugar del cuerpo. Existe un gran interés en los VPH como causa de malignidad, particularmente en el cáncer cervical. Al menos 58 diferentes VPH han sido identificados usando técnicas moleculares, estableciendo su relación con tipos particulares de tumores ${ }^{1}$.

La replicación de los virus papiloma depende del grado de diferenciación de los queratinocitos; las partículas virales maduras sólo se detectan en los núcleos de los estratos granuloso y córneo. Los efectos citopáticos que se observan en el epitelio, tales como la presencia de inclusiones intra-citoplasmáticas o nucleares, o la vacuolización peri-nuclear que caracteriza a las células coilocíticas, son secundarios a la interferencia ocasionada por el virus en la diferenciación de la célula huésped ${ }^{1,2}$. Aún no se conoce cómo este virus tiene la capacidad de penetrar la piel intacta; se sospecha que los micro-traumas facilitan su acceso a las capas más profundas de piel y mucosas.
El VPH, a diferencia de otros virus, no crece en cultivos celulares, de una manera que permita la realización de ensayos antivirales adecuados. Por otro lado, en contraste a los herpesvirus, que codifican 72 proteínas virales, el VPH codifica sólo 9 a 10 tipos de proteínas, carece de proteasas, ADN polimerasa, o de enzimas involucradas en el metabolismo de los nucleótidos. Todo esto ha impedido el desarrollo de terapias específicas contra el VPH.

La organización del genoma es la misma para los diferentes tipos de VPH y consiste en tres regiones:

- E (early-temprana): contiene genes para la codificación de proteínas reguladoras, transformadoras y replicadoras.

- L (late-tardía): contiene genes para la codificación de proteínas estructurales de la cápside.

- Regiones no codificantes.

La clasificación vigente del VPH se basa en forma exclusiva en la caracterización del genoma; se considera que se trata de un nuevo tipo si la región L1 -la parte menos variable del genoma del VPH- presenta una homología menor de $90 \%$ con otros tipos conocidos de VPH. Cuando la homología se sitúa en el rango de 90 a $98 \%$ indica un subtipo, y cuando la identidad es mayor de $98 \%$, se considera que es una variante. Los tipos son designados por números y los subtipos con letras, siguiendo un orden cronológico con respecto a su descripción. De esta manera han sido identificados más de 130 tipos, aunque sólo unos 80 han sido completamente caracterizados. ${ }^{2}$

\author{
Pontificia Universidad Católica \\ de Chile, Santiago, Chile \\ U.D.A. Dermatología \\ Recibido: 18 de julio 2006 \\ Aceptado: 23 de marzo de 2007 \\ Correspondencia a: \\ Marcela Concha Rogazy \\ marcelaconchar@gmail.com
}




\section{Patogenia de la infección por virus papiloma}

El ciclo vital del VPH se inicia con la infección de la capa basal de las células epiteliales, donde el virus expresa las proteínas E1 y E2 asociadas a la replicación y transcripción del ADN viral. Las proteínas E5, E6 y E7 son capaces de inducir la proliferación de las células basales y para-basales, provocando la hiperplasia epitelial. En las capas más superficiales de la epidermis se expresan las proteínas L1 y L2 que codifican la cápside y posterior ensamblaje de las partículas vira$\operatorname{les}^{1,2}$.

La inmunidad celular y la inmunidad innata son probablemente los factores más importantes en la resistencia del huésped, lo que es sugerido por el infiltrado de células $\mathrm{T}$ y la necrosis celular que se observa en el sitio de regresión de las verrugas, así como la participación de las células presentadores de antígenos y la secreción de citoquinas pro-inflamatorias. El receptor celular para el VPH parece ser una integrina del tipo $\alpha 6 \beta 4$, presente en la superficie de los queratinocitos de la capa basal. La respuesta innata está manifestada por la presencia de los receptores Toll (Toll-like receptors), definidos como 10 receptores de reconocimiento de patógenos existentes en las células presentadores de antígenos, activados por distintas proteínas microbianas y partículas virales, permitiendo una rápida respuesta a la infección por medio de la secreción de citoquinas pro-inflamatorias. Nuevos fármacos inmunomoduladores (imiquimod y resiquimod) son capaces de activar estos receptores ${ }^{3}$. La inmunidad humoral está descrita con la presencia de anticuerpos anti-cápside del VPH, y la transferencia pasiva de imunidad ya fue demostrada.

Las proteínas virales E6 y E7 participan en el proceso de oncogénesis. La proteína E6 de los tipos 16 y 18 de VPH tiene la capacidad de interactuar con proteínas celulares de la regulación del ciclo celular. Dentro de las proteínas que son degradadas, destaca la proteína p53, cuya misión es proteger la integridad del genoma durante el ciclo celular, impidiendo que se propaguen mutaciones a las células hijas que pueden evolucionar hacia una neoplasia. La proteína E7 coopera con la E6 en la inmortalización de los queratinocitos, interactuando con proteínas reguladoras del crecimiento celular como p107 y p130, relacionadas con el gen pRB, ciclina A y los factores de transcripción de la familia AP1.

Es imposible evitar el contacto con el VPH; como ejemplo, tan solo los tipos virales mucosos se encuentran en alrededor de $75 \%$ de la población femenina de E.U.A., siendo estas mujeres capaces de eliminar el $80 \%$ del VPH a lo largo de dos años ${ }^{3}$. Los condilomas acuminados o verrugas genitales son lesiones benignas producidas por el VPH de los tipos 6 y 11, en tanto los VPH oncogénicos 16 y 18, generalmente se asocian, a lesiones subclínicas, neoplasias intra-epiteliales $\mathrm{y}$ cáncer anogenital ${ }^{1-3}$.

Respecto a la portación cutánea, se conoce que el folículo piloso constituye un reservorio, y que en patologías como la psoriasis, la portación se encuentra francamente aumentada. El $60 \%$ de las verrugas comunes se resuelve dentro de 2 años; sin embargo, luego de este lapso de tiempo, tan solo $10 \%$ es eliminada en los siguientes 10 años.

Publicaciones recientes plantean la posibilidad de que ciertos tipos ( 5 y 8 ) de VPH tengan un papel en la patogénesis del cáncer cutáneo ${ }^{3,4}$.

\section{Diagnostico de las infecciones por virus papiloma humano}

Entre los métodos que se han desarrollado para el diagnóstico de las infecciones por VPH genital destacan:

- Ensayo en base a reacción de polimerasa en cadena (PCR-based assay- Amplicor VPH; Roche Diagnostic, Basel, Switzerland), disponible actualmente en Europa. Identifica a 30 genotipos, incluyendo 13 de alto riesgo u oncogénicos.

- Reacción de polimerasa en cadena y ADN/ARN viral mediante la prueba de captura de híbridos 2 (Hybrid capture ${ }^{\circledR}$ 2-HC2; Digene, Gathesburg, MD, E.U.A.). Prueba rápida en lote (menos de 2 horas) para detectar por lo menos 13 genotipos oncogénicos.

- El Programa para la Tecnología Apropiada para la Salud (PATH), en colaboración con Arbor Vita Corporation (E.U.A.), está desarrollando una segunda prueba, una tira de flujo lateral, para la detección de la proteína E6 en los tipos oncogénicos de $\mathrm{VPH}$, en menos de 20 minutos.

El Colegio Americano de Obstetricia y Ginecología ha entregado una guía para la utilización de estas técnicas y recomendaciones para la interpretación de resultados, en conjunto con resultados citopatológicos y tecnología en el diagnóstico celular ${ }^{3,4}$.

El diagnóstico de las verrugas comunes se basa en su presentación clínica, su localización anatómica y su histología. En la mayoría de los casos no es necesaria la identificación del genotipo viral, ya que todos corresponden a tipos de bajo riesgo o benignos (VPH 11 en papilomatosis laríngea; verrugas vulgares: VPH 2, 27 y 57 ; verrugas planas: 3 y 10 ; manos y pies: VPH $1)^{1,2}$. 
Ninguno de los exámenes disponibles para la detección de genotipos mucosos ha sido aprobada por la Food and Drug Administration, para su utilización en tipos cutáneos. En el caso de estudios de carcinomas cutáneos no melanoma (VPH 5/8), lo ideal es realizar una RPC anidada, con el fin de identificar la presencia de la mayor cantidad de tipos cutáneos.

\section{Tratamiento de las verrugas cutáneas y ano-genitales}

En la actualidad, no existe algún fármaco específico contra el VPH, de uso sistémico, que presente un bajo perfil de toxicidad, y con eficacia comprobada. La solución ha sido la utilización de métodos terapéuticos que destruyen las células infectadas (físicos, químicos o quirúrgicos). En la literatura médica, múltiples publicaciones relatan terapias contra el VPH, pero lamentablemente se presentan escasos trabajos randomizados y con seguimiento a largo plazo (Tabla 1$)^{4-7}$.

Es llamativa la escasa diferencia en resultados de las distintas terapias utilizadas. Destaca la menor efectividad del podofilino, lo cual ha sido confirmado por sucesivos estudios comparativos.

En las terapias quirúrgicas (láser de $\mathrm{CO}_{2}$, electrocirugía y extirpación quirúrgica), no existen estudios que avalen este supuesto mayor porcentaje de éxito, en realidad estas tres terapias son equivalentes en resultados.

Fluoracilo. Aparece con un porcentaje mucho menor de recidiva, pero los estudios en los que se basa esta afirmación presentan un número insuficiente de pacientes y su metodología es poco clara. En la actualidad es poco utilizado, dada su escasa respuesta en la práctica clínica (similar respuesta que al podofilino), y la presencia de efectos colaterales, tales como considerables erosión e irritación ${ }^{5,6}$.

Crioterapia. Es la aplicación de nitrógeno líquido en la verruga, a través de un fino spray desde un cryojet, o congelando directamente la lesión con criosondas. El mecanismo de acción es la producción de una necrosis epidérmica y dérmica, junto a una trombosis de la microvasculatura dérmica. El tratamiento recomendado es cada dos o tres semanas, y en cada sesión se utiliza una técnica de: congelación -descongelación- congelación, hasta que aparezca un halo de congelación a unos pocos milímetros alrededor de la lesión. Esta técnica ha demostrado ser más efectiva que una sola congelación (Guía del Reino Unido para el tratamiento de verrugas genitales). La duración de la congelación aconsejada hoy en día es la que el paciente pueda tolerar. En un estudio de revisión de terapia, la criocirugía fue igual de efectiva que el ácido tricloro- acético y más efectivo que el podofilino ${ }^{5,6}$. Sorprendentemente, no existe evidencia suficiente sobre la efectividad de la crioterapia versus placebo, pero si que ésta debe ser aplicada por lo menos en dos congelaciones para ser más efectiva ${ }^{7}$.

Electro-cirugía, tratamiento con láser y extirpación quirúrgica. No es posible establecer las indicaciones claras para la elección del método quirúrgico, en general, ya que esto depende de la distribución de las lesiones, su tamaño y la experticia del cirujano. Los pacientes son tratados bajo anestesia local, la que muchas veces produce una separación y elevación de las lesiones exofíticas, facilitando la extirpación exacta y evitando el daño de la piel no afectada, con resultados quirúrgicos generalmente muy favorables. Si se destruye con mayor profundidad, se pueden producir fibrosis y cicatrices retractiles. No se han publicado estudios que muestren, en forma estadísticamente significativa, que alguna de las terapias quirúrgicas utilizadas sea mejor que otra. En verrugas genitales, los resultados son similares a la criocirugía y mejores que el podofilino.

Todos los miembros del equipo que utilizan, tanto la electro-cirugía como la cirugía con láser, deben usar mascarillas quirúrgicas y extractor de humo, dado la presencia de virus viable en los extractores ${ }^{5,6}$.

Cimetidina. Aumenta la respuesta inmunitaria bloqueando los receptores de las células T-supresoras. No existen en la literatura científica revisiones sistemáticas sino, tan solo, trabajos randomizados con escaso número de pacientes, por lo cual su respuesta no es clara en relación a las terapias tópicas (crioterapia y ácido salicílico) $)^{5,6}$.

Inosine pranobex. Esta molécula es también un inmunomodulador inespecífico como la cimetidina, pero existe una mayor evidencia de su eficacia. Hay dos estudios randomizados que concluyeron una leve diferencia en relación al placebo, con dosis de 1 gr 3

\begin{tabular}{|c|c|c|c|}
\hline Tratamiento & $\begin{array}{c}\text { No de } \\
\text { tratamientos }\end{array}$ & $\begin{array}{c}\text { Porcentaje de éxito } \\
(\%)\end{array}$ & $\begin{array}{c}N^{\circ} \text { de recurrencias } \\
(\%)\end{array}$ \\
\hline Acido tricloro-acético & 4,0 & $64-81$ & 36 \\
\hline Podofilino & $3,4-6,7$ & $38-79$ & $21-65$ \\
\hline Podofilotoxino & 3,2 ciclos & $68-88$ & $16-34$ \\
\hline Fluoracilo & $2-2,5$ ciclos & $68-97$ & $0-8$ \\
\hline Crioterapia & 2,6-3,2 ciclos & $70-96$ & $25-39$ \\
\hline $\mathrm{CO}_{2}$ láser & $1,0-2,0$ & $72-97$ & $6-49$ \\
\hline Electro-cirugía & 1,3 & $72-94$ & $25-51$ \\
\hline Cirugía & 1,1 & $89-93$ & $19-22$ \\
\hline
\end{tabular}


veces al día por un mes. Se utiliza como terapia adyuvante a la crioterapia, al ácido salicílico, y al podofilino ${ }^{5,6}$.

$\alpha$-interferón. Ha demostrado su eficacia en forma tópica y sistémica, sólo en trabajos randomizados, con pequeños grupos de pacientes. Lo más significativo ha sido la reducción del área comprometida por la verruga, usándose como terapia coadyuvante junto al podofilino $^{5,6}$.

Imiquimod. Es un análogo de nucleótidos que, aplicado en forma tópica, actúa como un modificador de la respuesta inmune, induciendo la producción de $\alpha$ interferón y factor de necrosis tumoral (FNT- $\alpha$ ). Estas citoquinas aumentan la respuesta celular de los linfocitos T-helper (Th)1, incrementando la producción de $\gamma$ interferón, el que, a su vez, activa a los linfocitos citotóxicos. Además, es capaz de estimular en forma directa las células NK (natural killer) y las células de Langerhans.

Actualmente se comprende la importancia de la respuesta inmune innata (barreras epiteliales, fagocitos y complemento) y, en especial, de las células dendríticas y macrófagos, para activar una respuesta inmune específica. El imiquimod utilizado en forma tópica actúa como un ligando de los receptores Toll-like 7, induciendo la producción de $\alpha$ interferón y otras citoquinas pro-inflamatorias.

Existe una segunda generación de moléculas, tales como el resiquimod, que es capaz de activar los receptores Toll-like 8, que se encuentran actualmente en fase de evaluación para patologías virales, tales como infecciones por virus herpes simplex. En su conjunto, estos modificadores de respuesta se presentan como una opción terapéutica promisoria.

Los pacientes deben aplicarse el imiquimod al 5\% crema, una vez al día, (al acostarse), generalmente tres veces por semana, durante hasta 16 semanas. Se ha ensayado hasta tres veces al día, según tolerancia del paciente, con resultados similares. Son comunes las reacciones inflamatorias locales, en forma moderada a grave, las que se resuelven al suspender la terapia durante dos semanas. Su eficacia está demostrada en las verrugas genitales, con una respuesta local hacia las ocho semanas de uso, muy por el contrario a terapias que actúan en forma inmediata (ácido tricloroacético y podofilino). En las verrugas cutáneas su uso diario, nocturno, oclusivo, disminuye el área en verrugas recalcitrantes, junto a otras terapias coadyuvantes ${ }^{5,6}$.

\section{Tratamiento específico de las verrugas cutáneas}

Ácido salicílico. La efectividad de este queratolítico e irritante local, es similar a la crioterapia, lo cual fue demostrado en un meta-análisis, con la ventaja de que puede ser aplicado por el propio paciente, y a un menor costo económico. El sistema de revisión sistemática Cochrane 2006 demostró que la efectividad del ácido salicílico era mejor que el placebo. La mayoría de los estudios analizados eran de baja calidad metodológica. Además se encontró gran heterogeneidad entre los estudios en cuanto a diseño, metodología y resultados ${ }^{7}$. La aplicación debe ser muy constante, en forma diaria, en las noches (oclusivo), retirando previamente la capa de queratina que recubre las verrugas. Los efectos adversos pueden ser considerables, por lo cual los pacientes deben graduar la utilización según tolerancia. No debe utilizarse en áreas extensas, ni en altas concentraciones, especialmente en niños, ya que se ha reportado toxicidad sistémica. Se utiliza en forma asociada, en verrugas recalcitrantes (ácido salicílico + crioterapia + imiquimod $)^{6}$.

Inmunoterapia de contacto. El dinitro-clorobenzeno y la difenciprona pueden ser usados como sensibilizadores de contacto en pacientes con verrugas recalcitrantes. La solución es aplicada en $1 \mathrm{~cm}^{2}$ de piel sana, en la cara interna del brazo no dominante, para provocar una sensibilización y luego, se aplica directamente en la verruga. Este tratamiento no se utiliza en verrugas faciales ni en genitales, pues puede producir reacciones adversas mayores (ampollas). Sólo dos trabajos randomizados, con una escasa cantidad de pacientes, ha demostrado una eficacia mayor al placebo. En la actualidad se prefiere el uso de la difenciprona, dada la presencia de un riesgo teórico de mutagenicidad del dinitro-clobenceno ${ }^{6}$.

Bleomicina intralesional. Es considerada una terapia de tercera línea en las verrugas cutáneas. Presenta actividad anti-mitótica, uniéndose al ADN, y actividad antiviral. Se han publicado cuatro trabajos randomizados y controlados, con una evidencia poco sustentable. En uno de ellos, se obtuvieron los mismos resultados con diferentes concentraciones $(0,25 \%$ versus $1,0 \%)$. La infiltración debe ser superficial hasta lograr el blanqueamiento total de la verruga, produciéndose luego dolor y, en ciertos casos, rezume hasta la formación de una escara, al tercer día post terapia. El fármaco debe ser usado con precaución en las zonas periungueales, dado el riesgo de comprometer la matriz. Es teratogénico en el embarazo, aunque no se han demostrado efectos sistémicos similares a los observados cuando se utiliza como quimioterapia en el cáncer ${ }^{6}$.

\section{Tratamiento específico de las verrugas genitales}

Ácido tricloro-acético. (TCA) Junto al ácido bicloroacético (BCA) son agentes cáusticos que destruyen las verrugas por coagulación química de las proteínas 
y destrucción directa del ADN viral. Pese a que estas preparaciones son ampliamente utilizadas, no han sido completamente estudiadas (no existen publicaciones de BCA). Sólo se reportan dos estudios randomizados, comparativos entre crioterapia y TCA, con resultados de eficacia similares, y un tercer estudio comparativo, como adyuvante a la terapia con podofilino, sin mostrarse mayor mejoría con el uso conjunto de ambas terapias, en comparación con podofilino solo. Es el tratamiento de elección en mujeres embarazadas, con una efectividad de $\sim 90 \%$ y una recurrencia de $\sim 6 \%$. Es un tratamiento económico, pero requiere de una colocación con extremo cuidado, ya que, cuando se aplica en forma excesiva, puede dañar áreas adyacentes. Se aplica una pequeña cantidad directamente sobre la verruga, se deja secar, desarrollándose un color blanco en la verruga. Si produce mucho dolor se neutraliza, $\mathrm{y}$ generalmente se utiliza en forma semanal ${ }^{5,8}$.

Resina de podofilino o podophyllum. El podofilino es un extracto alcohólico de rizomas y raíces de plantas (Podophylum peltatum y P. emodi), que presenta un efecto anti-mitótico al unirse en forma irreversible a la tubulina, siendo capaz además de destruir los viriones del VPH en $85 \%$ de la verrugas tratadas. Estos extractos no son estandarizados, y se han descrito efectos mutagénicos (por los compuestos flavonoides quercetina y kenferol), y efectos sistémicos irreversibles de intoxicación: vómitos, coma, depresión respiratoria, hematuria, falla renal, y muerte por frenación medular. Por esta razón, se recomienda utilizar $<0,5 \mathrm{ml}$ de podofilino o un área menor a $10 \mathrm{~cm}^{2} \mathrm{y}$, para reducir la irritación local, lavar la zona en 1 a 4 horas post aplicación ${ }^{3,5,8}$.

Podofilotoxina. Extracto purificado de la podofilina, se une a los microtúbulos, inhibe las mitosis e induce necrosis de las lesiones, efecto que es máximo a los 3 o 5 días de uso y, en particular en las primeras dos semanas de aplicación. Se presenta en una concentración de $0,5 \%$ solución, gel o crema al $0,15 \%$. La aplicación se realiza dos veces al día durante 3 días, seguido por 4 a 7 días sin tratamiento. Este ciclo puede ser repetido durante 4 semanas. Los efectos adversos locales son moderados, especialmente cuando los resultados son favorables. No es oncogénico ni teratogénico $\mathrm{y}$, cuando es utilizado como quimioterápico a altas dosis, sólo se ha reportado malestar gastrointestinal y depresión medular transitoria.

En un reciente meta-análisis se reportó una alta eficacia, con un bajo porcentaje de recidiva. En un estudio randomizado se demostró que incluso su efectividad mejoraba si se utilizaba durante 8 semanas. No tiene efecto en verrugas muy queratinizadas, habiéndose reportado una baja efectividad en verrugas cutáneas $^{3,5,8}$.
Cidofovir. Es un análogo de nucleótidos que actúa sobre el ADN viral. Se aplica en crema al 1\%, 5 días a la semana. Se demostró su efectividad en pacientes portadores de verrugas peri-anales, con una efectividad promedio de $32 \%$ a las 12 semanas de uso, tanto en pacientes inmunocompetentes como pacientes con SIDA. Recurrencia de enfermedad: $3,7 \%$ al año de seguimiento. El único efecto adverso encontrado fue dolor, en un tercio de los pacientes. Cidofovir en crema se puede preparar a partir de las ampollas para uso parenteral, a un costo promedio US $\$ 1,000$ para dos semanas de tratamiento ${ }^{5,8}$.

Preservativos de látex. No cubren toda la superficie cutánea capaz de transmitir el VPH; son más efectivos en el caso de la prevención de infecciones transmitidas por medio de fluidos. No existe una evidencia clara en relación al beneficio del preservativo en la transmisión del VPH. Para realizar una siembra del virus, no es necesaria la penetración en el coito, ya que ésta puede producirse tan sólo con el contacto de genital con genital y manos con genitales. Para que exista una siembra, el virus se debe encontrar en su estado de virión, lo que sólo ocurre en lesiones proliferativas. Interesante fue el hallazgo, en un estudio randomizado, de mejoría en mujeres portadoras de neoplasias intra-epiteliales, y de parejas masculinas con menor índice de verrugas, cuando éstos utilizaban siempre preservativos ${ }^{5,8}$.

Vacunas. Tanto vacunas preventivas como terapéuticas se encuentran en actual desarrollo, constituyendo una gran esperanza en el tratamiento del VPH.

Vacunas profilácticas: Las primeras vacunas desarrolladas, con finalidad profiláctica, están conformadas por sub-unidades de pseudo-cápsides virales-PCV generadas por auto-ensamblaje de L1, la principal proteína capsular. Las vacunas contienen L1 PCVs de los virus VPH tipo 16,18, 6 y 11, aislados o combinados con sustancias estimuladoras de la respuesta inmune. La protección de estas vacunas es específica para cada tipo de virus y sólo es efectiva si se utiliza antes de la exposición al virus (en la práctica, antes de la primera relación sexual). Estas vacunas son polivalentes, incluyendo los tipos predominantes en la población a inmunizar y se colocan en tres dosis $(0,1$ mes y 6 meses) ${ }^{10,11}$.

Se han llevado a cabo ensayos clínicos de fase III para evaluar la vacuna cuadrivalente (Gardasil ${ }^{\circledR}$ de Merck, Sharp \& Dohme) que contiene los serotipos 6, 11,16 y 18 , en más de 25.000 participantes reclutadas de todo el mundo. También se encuentra en evaluación la vacuna bivalente genotipos 16 y 18 (Cevarix ${ }^{\circledR}$ de Glaxo SmithKline) esperándose su comercialización durante el año 2007. Los primero resultados con la vacuna cuadrivalente son extremadamente positivos: 
durante un período de dos años, comparado con el grupo placebo, no se ha observado ningún caso de neoplasia intra-epitelial, en aproximadamente las 6.000 mujeres vacunadas. Todavía existen varios aspectos importantes no conocidos, tales como la duración de la protección, la prevención de la infección y de la enfermedad causada por otros genotipos virales, y los beneficios globales de una vacunación universal. Se espera que sea altamente efectiva en la prevención de la infección por los tipos de VPH responsables de aproximadamente el $70 \%$ de los casos de cáncer de cuello uterino (tipos 16 y 18), y de $\sim 90 \%$ de los casos de verrugas genitales (tipos 6 y 11) $)^{5,10,11}$.

La FDA aprobó su comercialización en E.U.A., en junio 2006 y se estima su lanzamiento comercial en Chile dentro de pocos meses.

Vacunas terapéuticas: Inducen inmunidad contra E6 y E7, y otros antígenos expresados en el epitelio infectado pos VPH, e inducen una respuesta antígenoespecífica mediada por linfocitos T. Estas vacunas serían capaces de inducir una regresión tumoral y se utilizarían como terapia oncológica. Se han diseñado: vacunas recombinantes proteicas o peptídicas, vacunas PCV-L1, vectores recombinantes y vacunas con ADN específico ${ }^{3,10,11}$.

\section{Conclusiones}

Los factores que influyen en la selección de la terapia son el tamaño, la localización, el número y morfología de las lesiones, el sitio anatómico afectado, la preferencia del paciente, el costo del tratamiento, la conveniencia, los efectos adversos y la experiencia del profesional.
El podofilino/podofilotoxino y el ácido salicílico constituyen la primera opción costo-beneficio en verrugas genitales y cutáneas, respectivamente. La segunda línea de tratamiento para verrugas cutáneas vulgares es la crioterapia, mientras que en las recalcitrantes se incluye la crioterapia, electro-cirugía y la bleomicina intra-lesional, en conjunto con imiquimod oclusivo, inosine pranobex o dinitro-clorobenzeno. En el caso de verrugas genitales, la primera y segunda línea incluye el tratamiento quirúrgico y el uso de imiquimod. La crioterapia y el ácido tricloro-acético son generalmente terapias de tercera línea, salvo en el caso de verrugas del meato urinario y mujeres embarazadas, respectivamente. En las verrugas recalcitrantes genitales, se recomienda emplear terapia de tercera línea, incluyendo cirugía, en combinación con imiquimod y cidofovir ${ }^{5,7}$.

Las vacunas son el arma terapéutica del futuro, aportando conocimiento del comportamiento viral y el desarrollo de posibles terapias específicas contra el VPH.

\section{Resumen}

Tanto el diagnóstico como el tratamiento de la infección producida por el virus papiloma humano y el cáncer asociado a este virus, nos plantean uno de los mayores desafíos en la última década. Las principales dificultades radican en la identificación del genotipo viral, la ausencia de una terapia antiviral efectiva y las altas tasas de recurrencia y persistencia a pesar de la terapia empleada. Se presenta un resumen de la terapia disponible en la actualidad.

\section{Referencias}

1.- Fazel N, Wilczynski S, Lowe L. Clinical, histopathologic and molecular aspects of cutaneous human papillomavirus infections. Dermatol Clin 1999; 17: 521-36.

2.- Beutner K. Human papillomavirus and human disease. Am J Med 1997; 102: 9-15.

3.- Kenneth A A. Diagnosis and management of human papillomavirus infections. Pediatr Infect Dis J 2005; 24: 1007-8.

4.- Frazer I H, Cox J T, Mayeaux E J Jr, Franco E L, Moscicki A B, Palefsky J M, et al. Advances in prevention of cervical cancer and other human papillomavirusrelated diseases. Pediatric Infect Dis J 2006; 25: S65-S81.

5.- Fox P A, Tung M Y. Human papillomavirus, burden of illness and treatment cost considerations. Am J Clin Dermatol 2005, 6: $365-81$.

6.- Bigby M, Gibbs S. Warts. Clin Evid 2005; 14: 14- 27.

7.- Gibbs S, Harvey I. Topical treatments for cutaneous warts. Cochrane Database Syst Rev 2006

8.- Buck HW. Genital warts. Clin Evid 2005; 14: 1-13.
9.- Beutner and Ferenczy. Therapeutic approaches to genital warts. Am J Med 1997; 102: 28-37.

10.- Kadish A S, Einstein M H. Vaccine strategies for human papillomavirus-associated cancers. Curr Opin Oncol 2005; 17: 456-61.

11.- Villa L L Cos, Petta C A, Andrade R P, Ault K A, Giuliano A R, et al. Prophylactic quadrivalent human papillomavirus (types 6 , 11, 16, and 18) L1 virus-like particle vaccine in young women: a randomised double-blind placebo-controlled multicentre phase II efficacy trial. Lancet Oncol 2005; 6; 271-78. 